\title{
Personajes y discurso emocional en las campañas de la DGT. Análisis de los spots de 2007-2011
}

\author{
Rosario Segura García \\ Universidad de Granada \\ rosariosegura@ugr.es
}

\begin{abstract}
Resumen:
En este trabajo se muestra la importancia de la apelación emocional como medio persuasivo en los spots publicitarios de la Dirección General de Tráfico desde 2007 hasta 2011, identificando las emociones más representadas en el discurso audiovisual, el perfil del sujeto de dichas emociones, y su relación con el objeto del spot. La metodología utilizada ha sido la del análisis de contenido, cuantitativo y cualitativo, partiendo de la observación directa de una serie de variables seleccionadas, tratadas después estadísticamente, de forma absoluta y en relación con otros valores.
\end{abstract}

Palabras Clave: personajes; emociones; Dirección General de Tráfico; spot; campaña publicitaria.

\section{Characters and emotional speech in the campaigns of Spanish Traffic Department. Analysis of 2007-2011 spots}

\begin{abstract}
:
This work shows the importance of emotional appeal in persuasive medium for spots of Spanish traffic Department from 2007-2011, and I identify the emotions represented in the visual speech, the subject profile of these emotions, and their relationship with the object of spot. The methodology has been: content analysis, quantitative and qualitative, based on direct observation of a number of selected variables, and treated statistically, absolutely and in relation to other values.
\end{abstract}

Key Words: characters; emotions; Spanish Traffic Department; spot; advertising campaign.

\section{Referencia normalizada:}

Segura García, R. (2014): Personajes y discurso emocional en las campañas de la DGT. Análisis de los spots de 2007-2011. Historia y Comunicación Social. Vol. 19. Núm. Especial Febrero. Págs. 355-363.

Sumario: 1. Introducción. 2. Metodología. 3. Análisis. 3.1. Emociones y racionalidad en el discurso audiovisual. 3.2. Tipos de emociones destacadas. 3.3. Sujeto y género de emociones. 4. Referencias bibliográficas. 


\section{Introducción}

Esta investigación se ha centrado en analizar los aspectos emocionales de las campañas publicitarias de la Dirección General de Tráfico porque constituyen actualmente un tema de interés en la investigación de las ciencias sociales y especialmente en publicidad. Desde hace varias décadas, diversos sociólogos han detectado la falta de atención que se ha prestado a las emociones como factor relevante a la hora de analizar los fenómenos sociales, como la constitución de las sociedades o las relaciones entre individuos, ya que tradicionalmente se ha puesto el acento solo en la lógica racional. Entre otros, quienes han reivindicado el papel de las emociones en la sociedad están Illouz (2009) Arlie R. Hochschild (2008), Dixon (2003), y en España Eduardo Bericat (2000).

También desde la psicología, desde el siglo XIX se presta atención a este fenómeno para explicar la conducta humana tanto desde el conductismo como el psicoanálisis. En marketing y economía, en las últimas décadas, las emociones han constituido un factor a tener en cuenta de cara a explicar conductas de compra, incentivo de consumo, etc. Lógicamente para la publicidad, es un elemento clave a tener en cuenta. Este tema puede abordarse no solo de cara al efecto en el consumidor, sino también desde una perspectiva interior al propio discurso.

Asimismo, en el campo de las ciencias biomédicas, como la neurología, se han realizado investigaciones muy interesantes que pueden ser aplicables tanto a la psicología como a la comunicación audiovisual y publicidad. Principalmente nos referimos a los trabajos realizados por el neurólogo Antonio Damasio.

Resulta realmente interesante el análisis realizado en el año 2009 acerca de cómo se desenvuelven en el cerebro las emociones relativas a un daño físico, o a un dolor moral. Las conclusiones de este investigador (Damasio, 2009) proceden de un experimento llevado a cabo con 13 voluntarios de la Universidad de Southern California (en Los Ángeles, EEUU), donde el científico portugués dirige el Instituto del Cerebro y la Creatividad. Después de escuchar historias reales que trataban de despertar en ellos sentimientos de admiración y de compasión en el sentido físico como de empatía social, se observó lo que ocurría en su cerebro mediante imágenes de resonancia magnética. Hasta ahora los estudios cerebrales sobre la compasión estaban limitados a los sentimientos que despierta en nosotros el dolor ajeno; ésta es la primera vez que se extiende este concepto en un sentido más amplio de compasión o empatía social y se aborda además la admiración.

En el caso de la visualización de emociones con daño físico, las emociones que se desencadenaban iban acompañadas de una reacción cerebral en cuestión de decimas de segundo, sin embargo en el caso en las que se trataba de un daño moral o social, tardaban unos seis u ocho segundo, sin embargo perduraban activas más tiempo. Según Damasio, el cerebro es capaz de distinguir emociones que tienen que ver con cuestiones físicas de las que tiene que ver con un ámbito moral o psicológico, y que son las que influyen en las relaciones interpersonales. Estos hallazgos resultan de 
interés no solo en neurología sino también para cualquier profesional que trabaje con emociones.

Por otro lado, la DGT desde su creación en 1959, ha tenido como finalidad la seguridad vial tanto de peatones como de conductores. En un principio, su interés principal se centró en la formación de una sociedad cuyo parque móvil se iba engrosando. Posteriormente, ante las elevadas tasas de siniestralidad, que no iban sino en aumento, ha tratado de reducirlas con diversas medidas, entre ellas, las campañas publicitarias.

El índice de mortalidad en los accidentes de tráfico ha ido disminuyendo considerablemente desde el año 2001, hasta llegar a un límite inferior al de 1974. Desde 2007 desciende además, no solo el número de fallecidos, sino el de víctimas en su conjunto. Aunque no es la única ni mucho menos, las campañas publicitarias han tenido una relevancia particular en esta evolución, junto a otro tipo de medidas, y especialmente las campañas audiovisuales. Además en 2012, por octavo año consecutivo, se ha reducido la tasa de mortalidad de los accidentes de tráfico en España como puede confrontarse en la Nota de prensa de la DGT del 3 de marzo del año 2012.

La proporción de fallecidos respecto al parque móvil en 2012, es la menor de la historia de la DGT. Es la primera vez en que el número de fallecidos en términos absolutos se sitúa por debajo del de 1962, fecha del primer spot y por primera vez, se sitúa por debajo de la media europea.

Las medidas que la DGT ha tomado en los últimos años podrían sintetizarse en las siguientes: incremento de publicidad especialmente audiovisual, campañas de divulgación en escuelas, medidas penales (prisión, pérdida de puntos y retirada de carnet) y mayor control de las fuerzas de seguridad (grado de alcoholemia, multas y control de drogas), principalmente.

La investigación que sigue trata de mostrar la importancia de la apelación emocional como medio persuasivo en los spots publicitarios de la Dirección General de Tráfico desde 2007 hasta 2011, identificando las emociones más representadas en el discurso audiovisual, el perfil del sujeto de dichas emociones, y su relación con el objeto del spot. Como se ha dicho al inicio, nos encontramos en una sociedad en la que las emociones ocupan un papel importante, pudiendo calificar nuestro entorno como perteneciente a una cultura.

Respecto a las campañas audiovisuales de la DGT podemos distinguir dos grandes tipos de spots: los meramente informativos, estructurados según una publicidad que podemos llamar racional, y según una publicidad emocional, en los cuales las emociones son la clave del discurso.

En cuanto a los personajes, ejercen un papel importante en la comunicación con el espectador ya que son el elemento con el que se va a identificar para emular su conducta y se ejercerá el efecto deseado. De ahí el interés en analizarlos. 
El análisis realizado se detiene en el año 2011. A partir del 2012, se produce un interesante cambio en el estilo publicitario de la Dirección General de Tráfico, con un singular estilo de comunicación, por lo que se deja pendiente de una investigación posterior.

\section{Metodología}

El objetivo de esta investigación es identificar la tendencia de varios factores:

- Recurso a una publicidad de tipo emocional o racional;

- Identificación de los tipos de emociones representadas en los spots;

- Identificación del género del sujeto de dichas emociones y comparación entre sujetos de emociones en cuanto al género.

La metodología empleada ha sido la siguiente: se ha utilizado una muestra aleatoria de los spots disponibles en la web de la DGT producidos entre 2007 y 2011 . La muestra representa un $28 \%$ del total de spots. Las variables escogidas han sido los diferentes tipos de emociones resultado de una síntesis, teniendo en cuenta las investigaciones de diversos autores como Goleman (1997), y A. Damasio (2003), respecto a las emociones primarias y secundarias, o primarias y sociales.

Nuestra síntesis ha sido concretar las diferentes emociones en: tristeza, miedo, ira, vergüenza sorpresa, y alegría sin cerrar la puerta a la aparición de otras que destaquen por su frecuencia.

La manera de contabilizar las variables y subvariables ha sido binaria: 0 no existe, 1 existe.

La hipótesis que se plantea es que la mujer aparece como sujeto de emociones en menor frecuencia que el hombre pero destaca como sujeto de una emoción particular que a simple vista ya puede intuirse, que es lo que denominaremos amor.

\section{Análisis}

3.1. Emociones y racionalidad en el discurso audiovisual de 2007 a 2011

En los años que transcurren del 2007 al 2011, la tendencia es a utilizar más la publicidad de tipo emocional que la de tipo meramente informativa o racional (gráfico 1) 


\section{Gráfico 1}

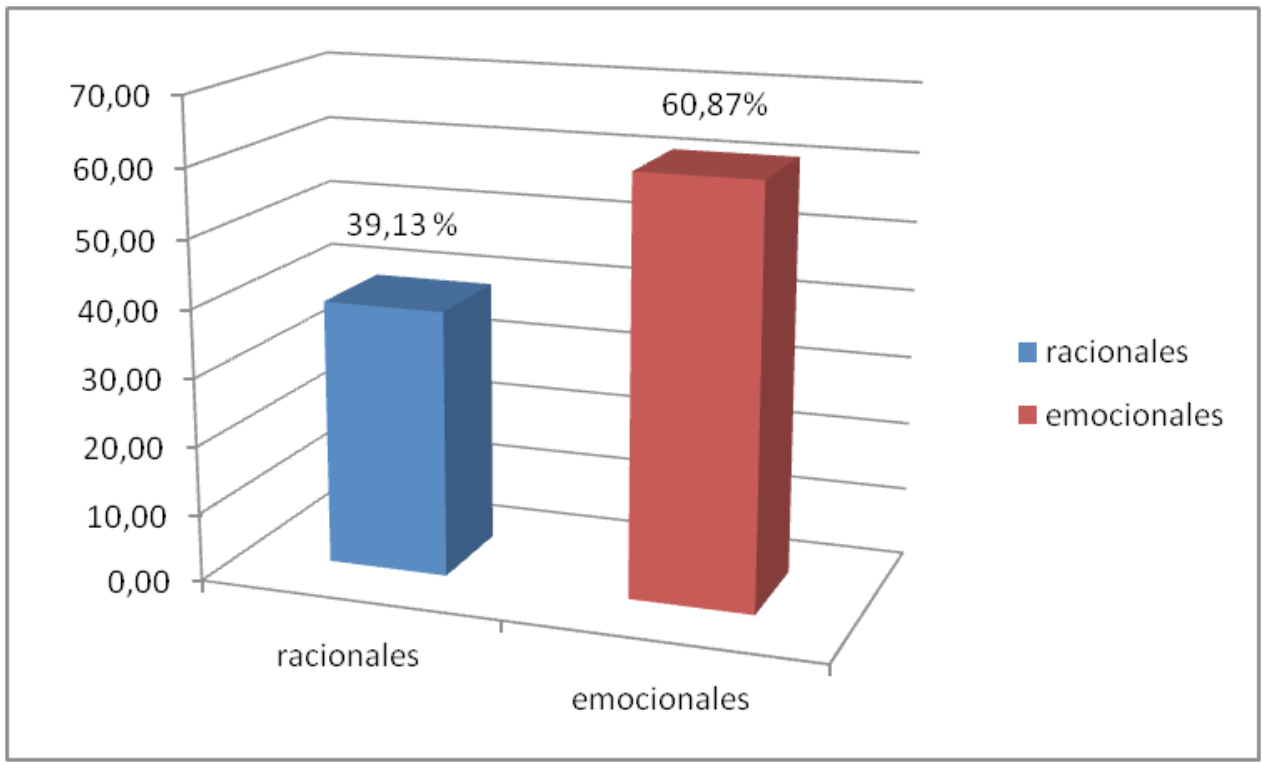

Hay una mayor intencionalidad de persuadir (60,87\%) que de enseñar (39,13\%), lo cual parece lógico pues la conducción de vehículos no es algo de reciente aparición, las normas son conocidas, se trata de respetarlas y dar motivos para ello. Un ejemplo de motivos para cuidar las normas es mostrar el daño que se infringe a los demás si no se tienen en cuenta, o las posibles consecuencias personales. La mera información persuade poco, y se olvida pronto, salvo que se repita con mucha insistencia. Un mensaje emocional, si está bien diseñado, permanece en la memoria si ha causado impacto.

\subsection{Tipos de emociones destacadas}

En primer lugar preciso el significado del término emoción y de cada uno de los tipos analizados:

- Emociones: acciones o movimientos, muchos de ellos públicos, pues producen movimientos en la cara, en la voz y conductas específicas, visibles para los demás, que se producen normalmente ante un estímulo externo.

- Alegría: diversión, entusiasmo, contento.

- Amor: hemos incluido bajo este término las relaciones de afecto que hemos encontrado. Parece que el término amor no es simplemente una emoción pero aquí lo consideramos en su acepción más simple y afectiva.

- Ira: rabia, cólera, irritación.

- Miedo: temor, susto, inquietud, pánico. 
- Sorpresa: reacción ante algo inesperado y agradable.

- Tristeza: pesar, pena, dolor, frustración, decepción, aflicción.

- Vergüenza: culpabilidad, remordimiento

Los tipos de emociones (gráfico 2) que aparecen con una frecuencia significativa y su porcentaje de aparición son los siguientes:

\section{Gráfico 2}

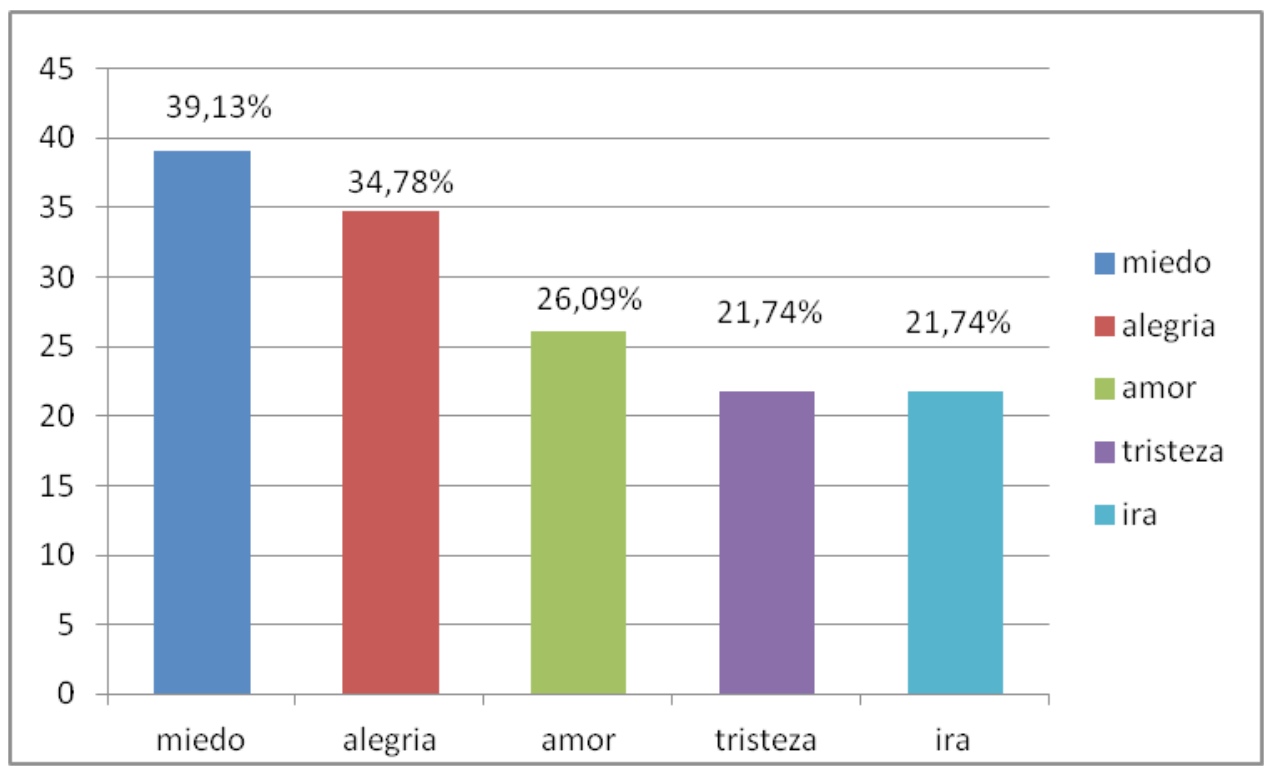

Se entiende la importancia del miedo $(39,17 \%)$, para transmitir al espectador la sensación de peligro, seguida de la alegría $(34,78 \%$ ), que muchas veces se presenta en una narrativa de contraste entre una situación de diversión que puede suponer un peligro para estar en condiciones de conducir después. Por otro lado, el amor (26,09\%) está presente en más de la cuarta parte de los spots, en el fondo de diversas situaciones. Y la tristeza y la ira, en igual proporción $(21,74 \%)$, son manifestación de los efectos inevitables de no haber respetado la norma.

\subsection{Sujeto y género de emociones}

El varón es el protagonista (principal o secundario) en todos los spots, frente a la mujer, que sólo actúa como tal en el $60 \%$ de ellos (gráfico 3), lo cual coincide con que el número de conductores implicados en accidentes es mayor en el caso de los varones que de las mujeres (prácticamente 3 veces más). Lógicamente hay spots en los que aparecen hombres y mujeres por eso no suman entre los dos el $100 \%$. 


\section{Gráfico 3}

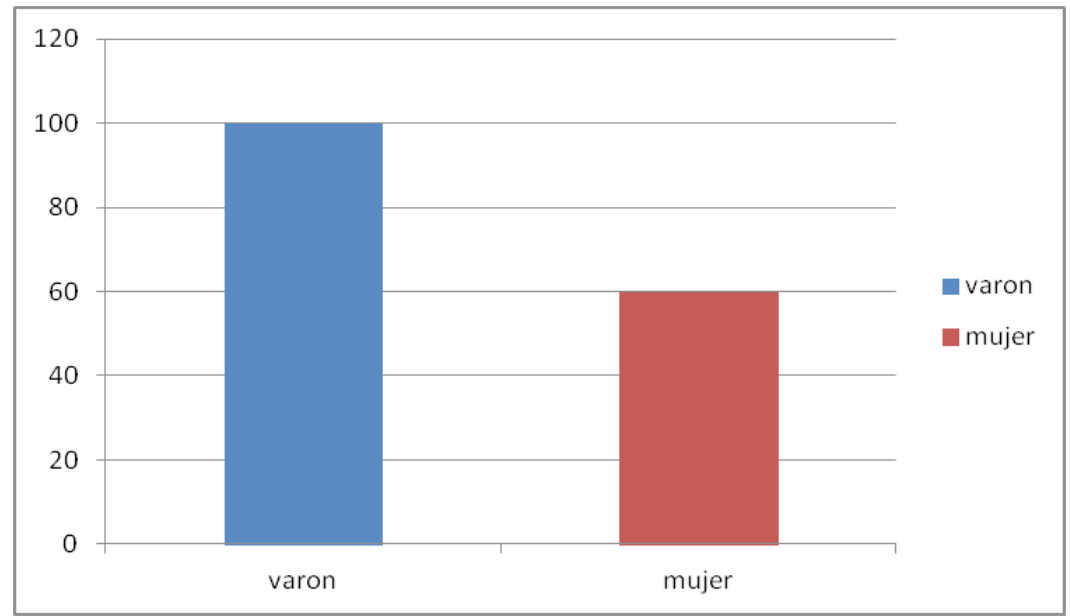

Hemos tomado como ejemplo el censo de conductores del 2011 y el número de conductores implicados en accidentes en vías interurbanas. Los resultados son que del total de accidentes, el $77,06 \%$ de conductores implicados eran varones y el $22,94 \%$ mujeres. Los censados varones son un 59\% del total, y las mujeres un $40 \%$. Como se aprecia todavía es mayor la diferencia en accidentes ya que es superior el número de varones censados que el de mujeres.

Respecto a la diferencia de género del sujeto de las emociones representadas, merece la pena destacar que mientras el varón representa por igual la alegría y el miedo (34,78\%), la mujer representa sobre todo el amor (30,43\%), con más frecuencia que el varón, (26,09\%), y la alegría (26.09\%). (Ver gráfico 4).

Gráfico 4, en porcentaje

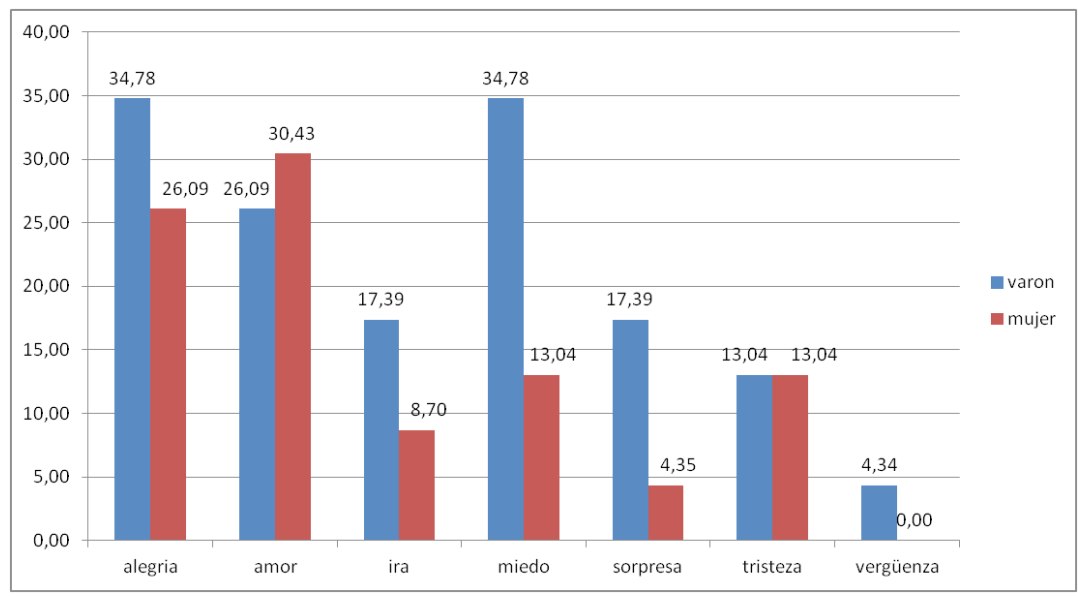




\section{Conclusiones}

Este análisis representa una tendencia que habría que confirmar con un análisis exhaustivo de todos los spots de la franja escogida (2007-2011). Según los resultados, la DGT ha recurrido en los años analizados a una publicidad de carácter principalmente emocional, ya que los mensajes de este tipo son más persuasivos: se graban más y se recuerdan mejor.

Se insiste especialmente en los efectos dramáticos que se derivan de un uso incorrecto del volante, por lo que la emoción más representada ha sido el miedo, en la línea de la enseñanza de lo que se debe evitar. A la vez, ese miedo se produce en muchos casos por el temor a perder a personas queridas, por lo que la tercera emoción más presente es el amor, representado prioritariamente por la mujer, dotada de una especial sensibilidad.

Se abren, además, varios campos de estudio en prospectiva:

- Comprobar si las emociones representadas potencian las buenas conductas en la conducción del target al que se quiere llegar (por ejemplo, si los varones retienen más el mensaje con las emociones representadas por hombres o por mujeres, o es al revés si hay una relación de afecto por ejemplo)

- Elaborar una serie de emociones sociales, como las llamaría Damasio, que sean útiles para que el discurso audiovisual adquiera más efectividad, puesto que la emoción más representada está relacionadas con un daño físico (miedo) $\mathrm{y}$, según este autor, esta última se genera con más rapidez pero permanece activa menos tiempo en el cerebro. En este sentido, la representación del amor realizada por alguna campaña, puede ser eficaz y acertada.

- Realizar un trabajo entre diversas áreas como psicología, publicidad y sociología en el que se aportaran datos útiles para investigar qué medidas son más efectivas en el mensaje audiovisual ya que las diversas medidas adoptadas por la DGT varían desde lo más instintivo y básico como el premio o castigo (ejemplo: multas, puntos, etc.) que correspondería a las emociones básicas de placer y dolor según Damasio, a otro tipo de las emociones básicas representadas en las campañas publicitarias, llegando a la transmisión de información a través de web, spots, y redes sociales de nivel intelectual.

\section{Bibliografía}

BERICAT, E. (2004). "La sociología de la emoción y la emoción en la sociología". En Papers, 62, 145-176, Disponible en: http://www.raco.cat/index.php/papers/ article/viewFile/25603/25437. [Recuperado el 29 de junio de 2013]. 
DAMASIO, A. (2009). "Cerebral and spinal modulation of pain by emotions". Disponible en: http://www.pnas.org/content/106/49/20900.full. [Recuperado el 29 de junio de 2013].

DAMASIO, A. (2003). En busca de Spinoza, neurobiología de la emoción y de los sentimientos. Barcelona: Ed. Crítica.

DGT (Dirección General de Tráfico de España):

Nota de prensa de 3 de enero de 2012. Disponible en: http://www.dgt.es/was6/ portal/contenidos/documentos/prensa_campanas/notas_prensa/NotasDePrensa0152.pdf . [Recuperado el 29 de junio de 2013].

Anuario estadístico de 2011. Disponible en: http://www.dgt.es/was6/portal/contenidos/es/seguridad_vial/estadistica/publicaciones/anuario_estadistico/anuario_ estadistico017.pdf. [Recuperado el 29 de junio de 2013].

Spots de los años 2007-2011. Disponibles en: http://www.dgt.es/was6/portal/ contenidos/visor multimedia/\#app=7f51\&f94f-selectedIndex=0. [Recuperado el 20 de junio de 2013].

GOLEMAN, D. (1997). Inteligencia emocional. Kairós: Barcelona

HOCHSCHILD, A. (2008). La mercantilización de la vida íntima. Apuntes de la casa y el trabajo. Katz: Barcelona

ILLOUZ, E. (2009). El consumo de la utopía romántica. Katz: Barcelona

\section{La autora}

Rosario Segura García es Licenciada en Filosofía, Máster en Filosofía Contemporánea e investigadora en Comunicación Audiovisual. Ha realizado diversos cursos sobre Comunicación y Tecnologías en la Universidad de Granada. Ha coordinado cursos sobre pensamiento, literatura y cine en la Escuela de Posgrado de dicha universidad. Su línea de investigación se encuadra en el ámbito de la cultura emocional, en el entorno audiovisual y en la red, tema sobre el que ha publicado varias comunicaciones en Actas de Congresos internacionales, y artículos en revistas de comunicación. Forma parte del grupo de investigación Ciber $A V$ "Cibercultura, Procesos Comunicativos y Medios Audiovisuales" (SEJ 508) de la Universidad de Granada. Es miembro de la Asociación española de investigación de la Comunicación (AE-IC), y de la Sociedad Latina de Comunicación Social 